\title{
Continuity of Care during Care Transition: Nurses' Experiences and Challenges
}

\author{
Else Cathrine Rustad $1,2,3^{*}$, Berit Seiger Cronfalk ${ }^{3,4,5}$, Bodil Furnes ${ }^{2}$, Elin Dysvik ${ }^{2}$ \\ ${ }^{1}$ Department of Clinical Medicine, Helse Fonna Local Health Authority, Haugesund, Norway \\ ${ }^{2}$ Department of Health Studies, Faculty of Social Sciences, University of Stavanger, Stavanger, Norway \\ ${ }^{3}$ Faculty of Health and Caring Sciences, Stord/Haugesund University College, Haugesund, Norway \\ ${ }^{4}$ Palliative Research Center, Ersta Sköndal Bräcke University College, Stockholm, Sweden \\ ${ }^{5}$ Department NVS, Karolinska Institute, Stockholm, Sweden \\ Email: *Else.Rustad@hvl.no
}

How to cite this paper: Rustad, E.C., Cronfalk, B.S., Furnes, B. and Dysvik, E. (2017) Continuity of Care during Care Transition: Nurses' Experiences and Challenges. Open Journal of Nursing, 7, 277293.

https://doi.org/10.4236/ojn.2017.72023

Received: December 22, 2016

Accepted: February 25, 2017

Published: February 28, 2017

Copyright $\odot 2017$ by authors and Scientific Research Publishing Inc. This work is licensed under the Creative Commons Attribution International License (CC BY 4.0).

http://creativecommons.org/licenses/by/4.0/

\begin{abstract}
The aim of this study was to gain increased knowledge about nurses' experiences of care transition of older patients from hospital to municipal health care, based on two research questions: How is nurses' experience continuity during care transition of older patients from hospital to municipal health care? How would nurses describe an optimal care transition? Nurses have a pivotal role during care transitions of older patients. More knowledge about their experiences is necessary to develop favorable improvements for this important period in the older patient's treatment and care. The study has a qualitative explorative design with follow-up focus group interviews. Nurses $(\mathrm{N}=$ $30)$ working in hospital $(n=16)$ and municipal $(n=14)$ health care were organized in five mixed focus groups during the period October-January 2014/2015. The focus groups met twice, answering the research questions following a previously circulated semi-structured interview guide. The interview analysis was inspired by content analysis. The analysis resulted in the themes "Administrative demands challenge terms for collaboration" and "Essentials for nursing determine optimal care transitions for older patients". Administrative demands may prevent nurses' professional dialogue and collaboration across health care levels. Older patients' best interests should be ensured through a collaborative relationship between hospital and municipal nurses, to form continuous care across health care levels. Clinical practice should be aware of essentials for nursing, which could influence and facilitate a more individualized and continuous transition for older patients.
\end{abstract}

\section{Keywords}

Care Transition, Municipal Health Care, Hospital Care, Continuity of Care, Focus Groups 


\section{Introduction}

A successful care transition from hospital to municipal health care is understood as the coordination of multiple factors to ensure continuity of the patient's treatment and care [1]. Due to a fragmented health care system in western countries, several health care levels, with different areas of competence and financial systems, together provide for the older patients [2]. As such, improvement of care transitions has been a stated goal both politically and within health care research [3]. Comparable to many other countries, Norwegian authorities have implemented the Coordination Reform [4]. By using incentives to skew treatment and care to municipal level, responsibilities and demands for nurses involved in care transitions of older patients are consequently altered [5]. Both hospital and municipal nurses play a key role during this important period of treatment and care, and they also have first hand contact with the older patients and their next of kin [6] [7].

\section{Background}

Norway has organized health care services in a New Public Management model, with the intention of making health care more efficient [8]. In this model the patient requests health care services from municipal health care through a purchaser-provider model. Municipalities organized in such a manner have separated nursing care from making decisions about the level of health care service the older patient are assigned [8].

Continuity of care can be understood as the extent that the patient perceives health care as coherent, connected and consisted with their needs [9]. Continuity of care includes three concepts: continuity of information, continuity of relation between patient and provider, as well as continuity of management-which is particularly important with complex chronic illness [9]. Adding to the conceptual descriptions, Hellesø \& Lorensen [10] suggest inter-organizational continuity of care, which addresses individual and organizational perspectives of continuity of care across health care levels.

In previous research, municipal nurses experience different professional challenges compared to hospital nurses [11]. Furthermore, municipal nurses experience low quality of discharge communication to be a major threat to patient safety [12]. As in other countries, and regulated by law, routines for discharging and receiving patients across health care levels are framed by cooperation agreements between hospital regions and associated municipalities [13]. Nevertheless, hospital nurses planning long-term care for the older patient often described it to be stressful when different stakeholders hold different values [14]. Obstacles such as patients' immediate needs and their limited preconditions to participate are found to explain nurses' low adherence to discharge routines [15]. In addition, multiple barriers are found to complicate nurses' continuity of information across health care levels (Olsen et al. 2013). Handover documents are often found incomplete regarding both medical and person-centered information about the patient [16] [17]. Electronic documentation systems are ex- 
pected to accommodate some of the instrumental challenges of information exchange [18]. However, within nursing practice, the synergism of collaboration is described as a core element [19] [20] [21]. Nevertheless, differences of perspectives, organizational structures and cultures might be important obstacles for collaboration across health care levels [21]. As such, improved communication and understanding of the opposite health care level could possibly contribute to increased collaboration between nurses during care transition [11].

Based on these considerations, we need more knowledge about both hospital and municipal nurses' collaborations to ensure favorable working conditions and continuity of care for older patients across health care levels. The aim of this study was to gain increased knowledge about nurses' experiences of care transitions of older patients from hospital to municipal health care, based on two research questions: how do nurses experience continuity during the care transition of older patients from hospital to municipal health care? How would nurses' describe an optimal care transition?

\section{Methodology}

\subsection{Study Design}

An explorative qualitative design with focus group interviews was chosen because care transition involves nurses from hospital and municipal health care with different perspectives and experiences. Focus group interviews are a common method within health care research, and are particularly productive given their multiple benefits within pedagogy, politics and research [22]. It was anticipated that through discussion among participants representing similar and dissimilar health care levels, new knowledge could emerge to illuminate the aim of the study. In addition, exchange of perspectives and experiences could contribute to valuable insight for our participants. Due to the scope of the study, the focus groups where gathered in two meetings (Figure 1). According to Malterud [23], arranging multiple meetings of focus groups is an option to initiate a reflective process in the participants that can be elaborated and clarified. As such, the first research question was addressed in the first focus group meeting, while the second research question was addressed in the second focus group meeting (Figure 1). In addition, based on the second research question, the participants were given quotations from a previous study exploring the experiences of patients aged 80 years or older during care transition [7]. The quotations highlighted topics concerning experiences of participation and continuity in terms of communication and responsibility during care transition [7], and were intended to be evocative, contributing to the participants' opportunity for reflective preparation prior to the second focus group meeting.

\subsection{Participants}

As nurses often busily work schedules, and as the intention was to bring nurses from different health care levels together in the same focus groups, a convenient sample of nurses was recruited to the study, because they were available with re- 


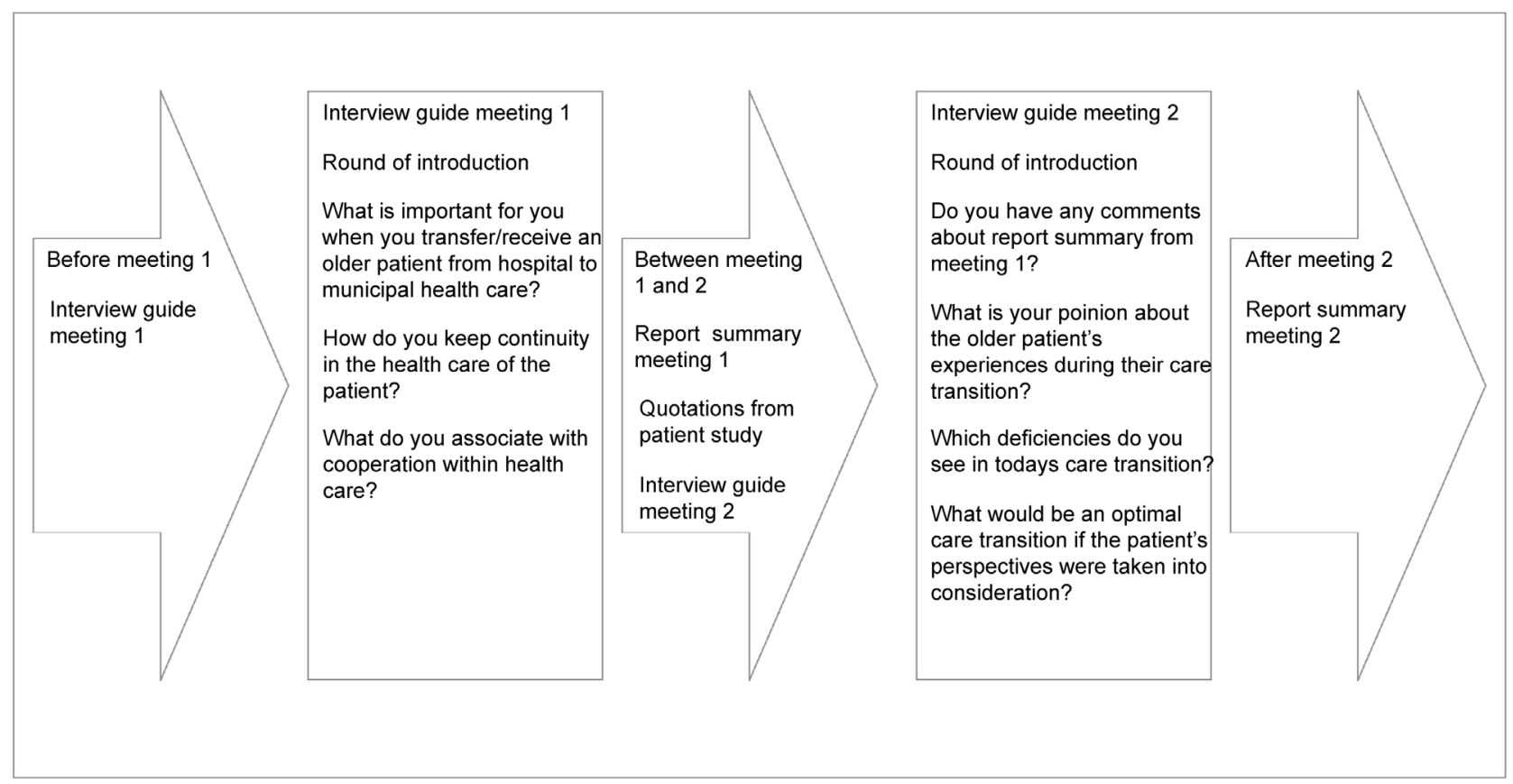

Figure 1. Schematic overview of focus group interviews, interview guides and participant confirmation, all documents sent participants by email.

gard to access, location, time and willingness. Nurses attending a postgraduate education at a local University College and nurses at a local hospital were informed about the study orally and in writing by the first author or by a Professional Development nurse staff at the hospital ward. Sample size was based on the focus group interviews information power as described by Malterud et al. [24] which indicates that the aim, sample specificity, theory, quality of dialogue and analysis strategy must be considered. The participants were divided into five focus groups, A-E, attempting equal distribution of nurses representing hospital and municipal health care in each focus group. Participants were contacted by email with the time and place of their first meeting. All participants were offered free lunch. A total of 30 nurses, 28 female and 2 male, participated in the study. All participants were attending a postgraduate education during the period of the focus group interviews. In addition, most of the participants had prior experiences as $\mathrm{RN}$ from other health care locations than the present. Background information is described in Table 1. From hospital care there were 16 nurses, representing 5 different hospitals, both larger university hospitals and smaller local hospitals nationwide. Municipal health care was represented by 14 nurses, from 9 different municipalities nationwide. The municipalities were of different sizes measured by number of citizens, and both towns and smaller villages were represented.

\subsection{Data Collection}

The focus group interviews were performed October/January, 2014/2015.All interviews were conducted at the University College of the participants' postgraduate education, during their lunch break or in the afternoon. The focus group 
Table 1. Participants' $(\mathrm{N}=30 \mathrm{RN})$ background information.

\begin{tabular}{|c|c|c|c|c|c|}
\hline \multirow[b]{2}{*}{ Focus group } & \multicolumn{5}{|c|}{ Background information } \\
\hline & Gender & Age (years) & Employment & $\begin{array}{c}\text { Experience as } \\
\mathrm{RN} \text { (years) }\end{array}$ & $\begin{array}{c}\text { Participation in } \\
\text { focus group } 1 \\
\text { and } 2\end{array}$ \\
\hline \multirow[t]{5}{*}{ A } & Female & 28 & Municipal health care & a & 1 and 2 \\
\hline & Female & 29 & Hospital & 4 & 1 and 2 \\
\hline & Female & 31 & Municipal health care & 3 & 1 and 2 \\
\hline & Female & 28 & Hospital & 3 & 1 and 2 \\
\hline & Female & 35 & Municipal health care & 10 & 1 and 2 \\
\hline \multirow[t]{9}{*}{ B } & Male & 29 & Hospital & $\mathrm{a}$ & 1 and 2 \\
\hline & Female & 23 & Hospital & 0,5 & 1 and 2 \\
\hline & Female & 34 & Municipal health care & 11 & 1 and 2 \\
\hline & Female & 26 & Hospital & 3 & 1 and 2 \\
\hline & Female & 42 & Hospital & 9 & 1 and 2 \\
\hline & Female & 27 & Hospital & 4 & 1 and 2 \\
\hline & Female & 33 & Municipal health care & 11 & 1 and 2 \\
\hline & Female & 29 & Municipal health care & 3 & 1 and 2 \\
\hline & Female & 25 & Hospital & 2 & 1 and 2 \\
\hline \multirow[t]{7}{*}{$\mathrm{C}$} & Female & 50 & Municipal health care & 24 & 1 and $b$ \\
\hline & Female & 44 & Municipal health care & 25 & 1 \\
\hline & Female & 25 & Hospital & 1 & 1 and 2 \\
\hline & Female & 48 & Hospital & 21 & 1 and 2 \\
\hline & Female & 36 & Municipal health care & 6 & 1 and 2 \\
\hline & Female & 25 & Hospital & 0,5 & 1 and 2 \\
\hline & Female & 34 & Hospital & 12 & 2 \\
\hline \multirow[t]{4}{*}{$\mathrm{D}$} & Female & 25 & Hospital & 1 & 1 and 2 \\
\hline & Female & 23 & Hospital & 1,5 & 1 and 2 \\
\hline & Female & 46 & Municipal health care & 10 & 1 and 2 \\
\hline & Female & 50 & Municipal health care & 26 & 1 and 2 \\
\hline \multirow[t]{5}{*}{ E } & Female & 52 & Municipal health care & 10 & 1 and 2 \\
\hline & Female & 53 & Hospital & 29 & 1 \\
\hline & Female & 26 & Hospital & 1,5 & 1 and 2 \\
\hline & Male & 43 & Municipal health care & 16 & 1 \\
\hline & Female & $\mathrm{a}$ & Hospital & a & 1 \\
\hline
\end{tabular}

a. Unknown; b. Was prevented from participating in 2. Meeting, sent answers to interview guide in writing.

interviews were carried out with one trained moderator and observer. The moderator led the focus group interview following a pre-tested interview guide covering the main topics. The interview questions are presented in Figure 1. The interview guide gave opportunity to follow issues that surface during the focus 
group interviews. In the beginning of each focus group interview it was emphasized that all participants were given time to describe their experiences. The observer took notes and asked additional follow-up questions if necessary. The focus group interviews lasted from $45 \mathrm{~m}$ until $1 \mathrm{~h} 31 \mathrm{~m}$, with a mean duration of 1 h $4 \mathrm{~m}$. After each focus group interview the moderator and observer discussed the dialogues and group dynamics. Finally, the moderator wrote a report summary from the focus group interview, which was approved by the observer before being sent to participants for validation.

\subsection{Ethical Considerations}

All participants had to sign a written consent prior to the focus group interview. They were assured of full confidentiality and could withdraw from the study at any time. The Norwegian Social Science Data Service and The Regional Committees for Medical and Health Research Ethics (Project number 2010/3342) have approved the study.

\subsection{Analysis and Interpretation}

Data from focus group meeting 1 (A1-E1) and data from focus group meeting 2 (A2-E2) were analysed separately as they address different topics of the aim of the study. Based on Graneheim and Lundman's [25] approach to content analysis the study was aiming for interpretation of its latent content;

1. The focus group interviews where transcribed verbatime and read carefully several times to get a sense of their whole.

2. Meaning units where identified in the text.

3. The meaning units where condensed to shorten the text without reducing its content.

4. Condensed meaning units were coded in accordance with their content.

5. The codes were compared based on their differences and similarities and sorted in sub-categories and thereafter grouped in categories.

6. Categories were abstracted in two themes.

\section{Results}

The analysis resulted in two main themes and four categories. In the following, the results will be organized in categories and clarified in selected quotations to illuminate the analysis and bring forward the voice of the participants.

\subsection{Administrative Demands Challenge Terms of Collaboration}

Analysis of data from meeting 1 (A1-E1) resulted in the theme "Administrative demands challenge terms of collaboration", interpreted from two categories; "Care transition rests on extensive routines" and "Professional collaboration is prevented by external conditions" (Table 2).

\subsubsection{Care Transition Rests on Extensive Routines}

Hospital nurses discussed care transition as stressful when many factors were 
Table 2. Theme, categories and sub-categories of "Administrative demands challenge terms for collaboration".

\begin{tabular}{|c|c|c|c|c|}
\hline Theme & \multicolumn{4}{|c|}{ Administrative demands challenge terms for collaboration } \\
\hline categories & \multicolumn{2}{|c|}{$\begin{array}{c}\text { Care transition rests on extensive } \\
\text { routines }\end{array}$} & \multicolumn{2}{|c|}{$\begin{array}{c}\text { Professional collaboration is prevented by } \\
\text { external conditions }\end{array}$} \\
\hline sub-categories & $\begin{array}{l}\text { Hospital nurses } \\
\text { perform extensive } \\
\text { preparations prior } \\
\text { to care transition }\end{array}$ & $\begin{array}{c}\text { The preliminary } \\
\text { municipal care rests } \\
\text { on hospital } \\
\text { preparations }\end{array}$ & $\begin{array}{l}\text { Misses the } \\
\text { opportunity for } \\
\text { professional } \\
\text { dialogue by phone }\end{array}$ & $\begin{array}{l}\text { Case manager } \\
\text { experienced as } \\
\text { intermediaries }\end{array}$ \\
\hline
\end{tabular}

considered during the final hours. Detailed agreements between hospital and municipal health care were followed, and the older patient's needs had to be taken into consideration, all within a limited period of time. Municipal nurses explained that they depended on preparations by hospital nurses. They often struggled with problems not always foreseen by hospital nurses, for example providing medications during weekends. The focus groups gave the opportunity to discuss the range of hospital care:

B1:

- (Hospital nurse) Usually, we end our care initiatives when the patient is discharged. And then you have the nursing summary for further follow up of the patient. But of course, I have special education in wounds, so sometimes I have sent along procedures from the Nursing Plan...or at least tried to...

- (Municipal nurse)It is very good with that kind of... you know, if not we just receive a patient with a wound, and it is sometimes frustrating when you receive a wound grade two or three you know, and there is no information about it

- (ECR) So what do you do then?

- (Municipal nurse) Well, we have to make a procedure ourselves. And we have a lot of qualified personnel on wound care (...) so we are fortunate. But what might happen is that it is overlooked, and if they come home during the weekend and there are a lot of nursing assistants, there might not be a nurse with the patient at that point and the patient is laying with a wound where the bandage should have been changed two days ago and they might develop....

\subsubsection{Professional Collaboration Is Prevented by External Conditions}

The participants unanimously missed using the telephone to talk to the nurse on the opposite health care level. Passing on information electronically was positive, improving the older patients' safety during care transition. Professional collaboration was understood to offer training if needed in the municipalities, often by inviting municipal nurses in to the hospital, which was easily done by telephone. In addition, verbal dialogue was sometimes necessary to make sure all concerns were understood and to exchange information that fell out of the electronic documentation system.

C1: 
- (Hospital nurse) (...) Sometimes we make a phone call to homecare if it is something very... or they are sick and there are things that they should pay extra attention to. And often this is due to next of kin feeling unsafe, that they find it scary and frightening or they feeling insecure, they don't feel safe and need additional information and that... well, that is the kind of thing that we discuss by phone instead of document in the sense of, for example, that the next of kin have said that they are not happy about the patient going home, for example.

In those care transitions where it was seen necessary to have a dialogue with the nurses on the opposite health care level, the participants usually had to communicate with the case manager. However, this was perceived to be insufficient due to their differences of perspectives. The case manager was described as having an administrative perspective, estimating older patients' right to assistance, and as not assessing older patients' needs from a nursing perspective.

A1:

- (Hospital nurse) But like us we have patients being admitted... and it is home care that knows and is familiar with the patient that they take care of on a daily basis. They talk to a case manager who maybe reads from the computer... perhaps a report... then it would help to call the nurse directly and talk... because that intermediary it is kind of...

- (Municipal nurse) We notice that a lot at the nursing home. When we receive the written documentation, after they have made the decision about the patient being admitted or having home care, the assessments are not correct in comparison with the patient when she arrives.

The theme "Administrative demands change terms for collaboration" was interpreted from the described categories. Care transition was experienced as a complex procedure in which nurses should fulfill extensive administrative duties. However, routines were framed by administrative agreements between health care levels, which sometimes limited the opportunities for professional exchanges and dialogue.

\subsection{Essentials for Nursing Determines Optimal Care Transitions for Older Patients}

Analysis of data from meeting 2 (A2-E2) resulted in the theme "Essentials for nursing determine optimal care transitions for older patients", interpreted from two categories; "Collaboration to identify older patients' best interest" and "Important elements for nursing practice" (Table 3).

\subsubsection{Collaboration to Identify Older Patients' Best Interest}

Findings indicate the older patient should be more involved during planning of the care transition. Often the nurses, along with next of kin, had suggestions for care that were presented to the older patient. The findings suggested that patient participation increased when documentation systems explicitly requested patients' opinions about their treatment and care. Agreeing about patients' needs for treatment and care after care transition was described as a difficult and ex- 
Table 3. Theme, categories and sub-categories of "Essentials for nursing determines optimal care transitions for older patients".

\begin{tabular}{|c|c|c|c|c|c|}
\hline Theme & \multicolumn{5}{|c|}{ Essentials for nursing determines optimal care transitions for older patients } \\
\hline categories & Collaboratic & $\begin{array}{l}\text { on to identify older patients } \\
\text { best interest }\end{array}$ & Important el & lements for nursi & ing practice \\
\hline $\begin{array}{l}\text { sub- } \\
\text { categories }\end{array}$ & $\begin{array}{l}\text { Patient } \\
\text { participation } \\
\text { prior to care } \\
\text { transition }\end{array}$ & $\begin{array}{l}\text { Professionals Professional } \\
\text { have different } \\
\text { perceptions of } \text { about long } \\
\text { patients needs }\end{array}$ & $\begin{array}{l}\text { Predictability } \\
\text { for involved } \\
\text { nurses and } \\
\text { patients }\end{array}$ & $\begin{array}{c}\text { Written } \\
\text { documentation } \\
\text { available for all } \mathrm{f} \\
\text { involved }\end{array}$ & $\begin{array}{l}\text { Municipal } \\
\text { nurses } \\
\text { flexibility and } \\
\text { competence }\end{array}$ \\
\hline
\end{tabular}

tensive process. Hospital nurses often found the patient's health status too poor for home care, while municipal nurses argued that patient's health most often improved in his or her own home.

D2:

- (Hospital nurse) But then I feel at the hospital that sometimes someone gets really poor health when they are in our ward and then, all they need is to be sent home and they function very well. But then it is difficult to know "is home care enough or do they need something more or what do they really need?" (...)

- (ECR) It is complex to consider the patients' real needs for assistance?

- (Municipal nurse)But it is very important to be open to...when the patient comes home that we come and visit and be a bit generous in the beginning, nor reduce the level of assistance afterwards.

- (Municipal nurse)We need to reassure the patient when he comes out (of hospital)...we are maybe told by the hospital that needs are the same as previously and so on but we need to discuss the things around technical utilities and make sure that they really do manage. But usually they are always better than we think they are.

Nurses across health care levels should share long-term goals for the older patient. All involved professionals should take part in creating the long-term goals, along with the older patient and their next of kin. As such, care transition should be done through shared professional planning:

A2:

- (Municipal nurse) I have been thinking about...I work at a nursing home and we see patients being admitted and coming back, and we do have sort of plans for the continuing treatment and care. We are not always updated on what has come forward in hospital, but have a more long-term and health-promoted plan for the patients who need it...who have chronic illnesses and are being cared for by different health personnel. It is in use but it is not the kind of...if one thinks of the good coordination in a good plan. It can be quite heavy and...

- (Nurse) We lack a shared goal.

- (Municipal nurse) Yes! The goal that is set by the patient and that we all are going to work towards. And why isn't it like that? You know, it would have been...I have often thought that it would be ok if we had sort of a template 
for... Now almost everybody has a care plan but still. It is missing so much.

\subsubsection{Important Elements for Nursing Practice}

Short notice of patient care transition was frustrating. Older patients weren't given time to digest their situation, and nurses had to fulfill the care transition within a short period of time. Predictability would give all involved parties time to prepare properly, in addition to bringing a feeling of safety and control to the older patients.

A2:

- (Hospital nurse) It would have been a bit better if we knew, perhaps one day in advance, when the patient will be offered care assistance, or where he is going to be transferred to, rather than one hour before we are off duty. I thought last time that we probably should phone them to let them know, but I don't have the time...or to tell them about the patient. But in other municipalities where they might know that the patient has been given a place in a nursing home several days in advance, then I have scheduled the time, during the day, to phone and update the place about his condition. That is absolutely the optimal way.

- (Municipal nurse) The most optimal for us...often when the case manager has...sometimes there are a lot of things that are not right, so it is not until we receive the PLO (Electronic documentation), and the medical summary and the nursing report are sent prior to the arrival of the patient, that we have the opportunity to check if we have the correct medications and equipment...do we need extra, e.g. oxygen, do we need to find a thermometer to hang on the wall, be more prepared. If not, we are suddenly taken by surprise, the decision office hasn't been aware that the patient needs oxygen, you know, and then we have to run to find it because the ambulance is waiting, and this should have been prepared a long time in advance. Because then you would have more direct contact between the nursing home and the hospital. If we do get the report in advance, we can make a phone call and ask "what do you mean by what is written?" Instead the patient arrives at ours at four o'clock, and then at eight o'clock we still haven't made his pill organizer, and then we have to call, and new staff are on duty, and there we are, going in circles.

- (Several participants)And you feel like a fool. You do not feel like a professional.

Written electronic documentation was important for patient safety. All those involved should have access to all documentation and preferably use the same data program. In addition, all documentation should be available prior to patient's care transition. There were extensive variations in municipalities' preconditions for treatment and care. Flexibility, where the nurse on site could decide the level of care needed-in dialogue with the older patient was described as optimal. Municipal nurses needed to possess the necessary competence to receive complex and severely sick older patients. 


\section{Discussion}

The analysis resulted in two themes, "Administrative demands change terms for collaboration" and "Essentials for nursing determine optimal care transitions for older patients", which will structure the following section.

\subsection{Administrative Demands Challenge Terms for Collaboration}

Our findings indicate that nurses experienced care transition demanding, having to fulfill extensive administrative duties in addition to taking care of the needs of older patients and next of kin. Planning and completing care transition is regarded as a nursing responsibility [20]. It seems that a substantial part of preparations for care transition are done during the final working hours, which might result in a work overload for the responsible nurses. Prior findings indicate that nurses prioritize between several important responsibilities during preparations for care transition, which might result in reduced compliance with discharge routines [15]. Our nurses described cooperation agreements between hospital and municipal health care as giving a clear regulation of responsibilities of each health care levels. However, they directed their attention to administrative tasks, often on behalf of the older patients' needs. The municipal nurses described receiving the patient in accordance with the cooperation agreements. Nursing-specific objectives such as providing medications for weekends and afternoons were often not fulfilled. Norwegian hospital regions and their associated municipalities are required by law to develop cooperation agreements, to provide a concrete division of duties and responsibilities between hospital and municipal health care [5] [26]. This agreement is similar to those in other Scandinavian countries [13]. As such, we argue that the organizational structures during care transitions appear to be insufficiently appropriate to nurses' working agenda.

Another finding was that nurses' initiatives for collaborative dialogue were often directed through case managers. This was experienced to be inadequate given their differences of perspectives. The initial purpose of a New Public Management organization of municipal care, was to divide the contractor role within municipal health care service from that of the provider of health care [8]. It appears that attempting to direct nurses' to intra-professional collaborations through liaising with the contractor is a challenging use of organizational structures. Previous research has often targeted communication and informational structures on an organizational level [27]. However, nurses have a long tradition of verbal reports, establishing common ground and continuity of care through two-way informational exchange [27] [28]. Recent research has focused largely on improvement of informational continuity across health care levels [16]. However, our findings clearly indicate the necessity of safeguarding essential features of nurses' collaboration, ensuring proper channels for alliance and dialogue in care transitions when needed.

Inter-organizational continuity of care consists of two perspectives: individual continuity of care in terms of provider-to-provider, and organizational continu- 
ity of care understood as structural coordination of care [10]. Similarly, our findings show how different perspectives of continuity of care contradict each other. Demands on an organizational level seem to be given priority at the expense of other nursing-specific tasks, possibly due to financial incentives adding weight to the priority of duties. Summing up, we suggest establishing organizational structures across the health care levels that facilitate nurses' collaboration, in order to improve continuity of care.

\subsection{Essentials for Nursing Determine Optimal Care Transition for Older Patients}

Hospital and municipal nurses in our study discussed patient participation in the process of planning the destination for the care transition. Patient participation is a formalized value that permeates all levels of health care [29]. Even so, patient participation is still found to be complex and insufficient [7] [30]. Some of our participants described it as a paradox that older patients' opinions about their treatment and care were not a fully formalized rubric in the electronic documentation system, which could be a way to optimize patient participation. Compared to the municipal nurses, the hospital nurses often had an impression of the older patient as frailer. The discussions underline the differences of perspectives and opinions of care in hospital and municipal health care. Exchange of views and opinions provided additional insight, which is also found in previous studies [21] [11] [31]. Our nurses suggested that to create long-term goals for patient treatment and care could optimize patients' experience of continuity, including in any subsequent admissions. The goals should stem from the older patient's motivation and perception of her own situation in combination with the professional assessment by hospital and municipal nurses. This perspective is in line with Haggerty et al. [9], who emphasises continuity of care where the patient's perceives whether care is experienced as continuous. We argue that a long-term aim could optimize and improve patient participation as well as lead to a joint effort in tailoring the care to older patients needs across health care levels.

In our focus groups, essentials for nursing were discussed as important for an optimal care transition. Following a timeline where all involved nurses, as well as the older patient, were prepared well in advance of the care transition was highlighted. A care transition that was not properly prepared seemed to compromise involved nurses' professionalism, and led to a poor start of the older patients' long-term municipal health care. Temporal aspects have previously been identified as influencing the quality of discharge of older patients [32].

There was agreement in the focus groups about the role of electronic documentation systems in safeguarding and improving care transitions, in line with previous studies [18]. Hospitals and municipals should optimally use the same documentation systems, and the information should be available for all involved well in advance of the care transition. Some of our nurses indicated that medical information from the medical doctor was often delayed until after the municipal 
nurses received the patient. In addition, there was no consensus in the focus groups about whether the electronic documentation should be supplemented with written documentations. There seem to exist parallel-varied routines, with different assumptions and practices in different municipalities. This might be explained by the historical evolution of municipal health care [8]. The approach should be standardized and not left to each individual nurse to anticipate what to do. There was a need for verbal dialogue if there was particularly sensitive information or exchange of competence. This was discussed as an important supplementary to the electronic documentation. The professional benefits of verbal dialogue are also found in previous research [33]. We argue that care transition does not just involve the passing of the patient from one point to another. Based on our findings it should, optimally, comprise the creation of a professional environment covering eventualities in the patients' treatment and care that might surface during and immediate after the care transition. In addition, through the focus groups it became clear that there are no communication channels known by the nurses where care transitions in themselves can be discussed and evaluated. We suggest that to ensure further continuity of treatment and care across health care levels there should be regular evaluation on a provider-to-provider level, in addition to the organizational level.

\subsection{Recommendations for Clinical Practice}

Clinical practice should be aware that a continuous care transition is influenced on an organizational level as well as a provider level. Clinicians are recommended to take into consideration the described essentials for nursing which could contribute to a more optimal care transition from both a nursing perspective as well as for older patients. Hospital and municipal nurses along with the older patient should create shared long-term goals for treatment and care during care transition. Important elements for nursing were experienced as influencing the possibilities of facilitating an optimal care transition. Cooperation agreements are suggested to clarify hospital and municipal health care responsibilities, but be flexible enough to facilitate nurses' professional judgements during care transitions. We recommend that hospital and municipal nurses should have open communication channel for discussing and evaluating care transitions.

\subsection{Methodological Considerations}

The group distribution ensured that participants representing the same municipality or hospital participated in the same groups, which increased the possibility of having some acquaintances with whom they were familiar. In addition, participants' different backgrounds contributed to depth and variation in their contributions. One limitation was that fewer male nurses participated in the study. However, that might reflect the gender distributions of nurses in Norway. In addition, the groups had approximately equal representatives from hospital and municipal health care, to facilitate a positive group dynamic. A balance between homogeneity and heterogenetic of the focus groups can reveal the diversity of 
experiences of participations [23]. Another possible limitation of the study might be the introduction of patient quotations as evocative material, which negotiates between steering and outlining the group dialogues [23]. All participants expressed recognition of older patients' experiences and built on this further with their own complementary reflections, and some participants brought handwritten notes of reflections to meeting 2 . As such, the patient quotations seemed to give the participants room for elaboration of the topics they found most important. In addition, arranging two meetings of each focus group gave an opportunity to address different features of care transition and follow up the discussions further, leading to a vast data material illuminating the aim. The analysis was done separately by the authors and discussed within the research team. Detailed descriptions of analysis and presentation of quotations seeks to ensure transparency. As we see it, these considerations might strengthen information power as an important aspect of internal validity [24]. Taking into consideration culture and context in an international perspective, as well as described methodological and analytical concerns, our findings might be transferable to similar situations.

\section{Conclusion}

Our study explores hospital and municipal nurses' experiences of continuity during care transition of older patients. Administrative demands sometimes limited the nurses' opportunities for establishing collaborative alliance and dialogue across health care levels. Care transitions should be continuous in accordance with the patients' best interests, provided through a collaborative relationship involving nurses from both health care levels. Essentials for nurses' practice should be taken into consideration when establishing administrative routines for care transition, in order to ensure collaboration across health care levels and provide continuous treatment and care for the older patient. When making improvements to care transitions, all dimensions of continuity of care should be taken into considerations.

\section{Acknowledgements}

We express our since regratitude to the 30 hospital and municipal nurses that participated in the study. Special thanks to the Western Norway Regional Health Authority and Stord/Haugesund University College for financial support.

\section{References}

[1] Coleman, E. (2003) Falling through the Cracks: Challenges and Opportunities for Improving Transitional Care for Persons with Continuous Complex Care Needs. Journal of American Geriatric Society, 51, 549-555. https://doi.org/10.1046/j.1532-5415.2003.51185.x

[2] Clegg, A., Young, J., Iliffe, S., Rikkert, M.O. and Rockwood, K. (2013) Frailty in Elderly People. The Lancet, 381, 752-762. https://doi.org/10.1016/S0140-6736(12)62167-9 
[3] Christensen, K., Doblhammer, G., Rau, R. and Vaupel, J. (2009) Ageing Populations: The Challenges Ahead. The Lancet, 374, 1196-1208. https://doi.org/10.1016/S0140-6736(09)61460-4

[4] Norwegian Ministry of Health and Care Service (2016) White Paper, Report No. 47 to the Storting (2008-2009) Samhandlingsreformen. Rett behandling-på rett stedtil rett tid [The Coordination Reform-Proper Treatment-at the Right Place and Right Time]. Norwegian Ministry of Health and Care Service, Oslo. https://www.regjeringen.no/no/dokumenter/stmeld-nr-47-2008-2009-/id567201/

[5] Romøren, T.I., Torjesen, D.O. and Brynjar, L. (2011) Promoting Coordination in Norwegian Health Care. International Journal of Integrated Care, 11. https://doi.org/10.5334/ijic.581

[6] Enderlin, C.A., McLeskey, N., Rooker, J.L., Steinhauser, C., D’Avolio, D., Gusewelle, R. and Ennen, K.A. (2013) Review of Current Conceptual Models and Frameworks to Guide Transitions of Care in Older Adults. Geriatric Nursing, 34, 47-52. https://doi.org/10.1016/j.gerinurse.2012.08.003

[7] Rustad, E., Furnes, B., BS, C. and Dysvik, E. (2016) Older Patients' Experiences during Care Transition. Patient Preference and Adherence, 10, 769-779. https://doi.org/10.2147/PPA.S97570

[8] Vabø, M. (2012) Norwegian Home Care in Transition-Heading for Accountability, Off-Loading Responsibilities. Health \& Social Care in the Community, 20, 283291. https://doi.org/10.1111/j.1365-2524.2012.01058.x

[9] Haggerty, J.L., Reid, R.J., Freeman, G.K., Starfield, B.H., Adair, C.E. and McKendry, R. (2003) Continuity of Care: A Multidisciplinary Review. British Medical Journal, 327, 1219-1221. https://doi.org/10.1136/bmj.327.7425.1219

[10] Hellesø, R. and Lorensen, M. (2005) Inter-Organizational Continuity of Care and the Electronic Patient Record: A Concept Development. International Journal of Nursing Studies, 42, 807-822. https://doi.org/10.1016/j.ijnurstu.2004.07.005

[11] Kirsebom, M., Wadensten, B. and Hedström, M. (2013) Communication and Coordination during Transition of Older Persons between Nursing Homes and Hospital Still in Need of Improvement. Journal of Advanced Nursing, 69, 886-895. https://doi.org/10.1111/j.1365-2648.2012.06077.x

[12] King, B.J., Gilmore-Bykovskyi, A.L., Roiland, R.A., Polnaszek, B.E., Bowers, B.J. and Kind, A.J.H. (2013) The Consequences of Poor Communication during Transitions from Hospital to Skilled Nursing Facility: A Qualitative Study. Journal of the American Geriatrics Society, 61, 1095-1102. https://doi.org/10.1111/jgs.12328

[13] Rudkjøbing, A., Strandberg-Larsen, M., Vrangbaek, K., Andersen, J.S. and Krasnik, A. (2014) Health Care Agreements as Tool for Coordinationg Health and Social Services. International Journal of Integrated Care, 14, e036. https://doi.org/10.5334/ijic.1452

[14] Denson, L.A., Winefield, H.R. and Beilby, J.J. (2013) Discharge-Planning for LongTerm Care Needs: The Values and Priorities of Older People, Their Younger Relatives and Health Professionals. Scandinavian Journal of Caring Sciences, 27, 3-12. https://doi.org/10.1111/j.1471-6712.2012.00987.x

[15] Graham, J., Gallagher, R. and Bothe, J. (2013) Nurses' Discharge Planning and Risk Assessment: Behaviours, Understanding and Barriers. Journal of Clinical Nursing, 22, 2338-2346. https://doi.org/10.1111/jocn.12179

[16] Olsen, R.M., Østnor, B.H., Enmarker, I. and Hellzén, O. (2013) Barriers to Information Exchange during Older Patients' Transfer: Nurses' Experiences. Journal of Clinical Nursing, 22, 2964-2973. https://doi.org/10.1111/jocn.12246 
[17] Flink, M., Glas, S.B., Airosa, F., Öhlén, G., Barach, P., Hansagi, H., Brommels, M. and Olsson, M. (2015) Patient-Centred Handovers between Hospital and Primary Health Care: An Assessment of Medical Records. International Journal of Medical Informatics, 84, 355-362. https://doi.org/10.1016/j.ijmedinf.2015.01.009

[18] Melby, L., Brattheim, B.J. and Hellesø, R. (2015) Patients in Transition-Improving Hospital-Home Care Collaboration through Electronic Messaging: Providers' Perspectives. Journal of Clinical Nursing, 24, 3389-3399. https://doi.org/10.1111/jocn.12991

[19] Hennemann, E.A., Lee, J.L. and Cohen, J.I. (1995) Collaboratin: A Concept Analysis. Journal of Advanced Nursing, 21, 103-109. https://doi.org/10.1046/j.1365-2648.1995.21010103.x

[20] Lemetti, T., Stolt, M., Rickard, N. and Suhonen, R. (2015) Collaboration between Hospital and Primary Care Nurses: A Literature Review. International Nursing Review, 62, 248-266. https://doi.org/10.1111/inr.12147

[21] Røsstad, T., Garåsen, H., Steinsbekk, A., Sletvold, O. and Grimsmo, A. (2013) Development of a Patient-Centred Care Pathway across Healthcare Providers: A Qualitative Study. BMC Health Services Research, 13, 121. https://doi.org/10.1186/1472-6963-13-121

[22] Kamberelis, G. and Dimitriadis, G. (2011) Focus Groups: Contingent Articulations of Pedagogy, Politics and Inquiry. In: Denzin, N.K. and Lincolc, Y.S., Eds., The SAGE Handbook of Qualitative Research, Vol. 4, Sage, Los Angeles, 545-561.

[23] Malterud, K. (2012) Fokusgrupper som forskningsmetode for medisin og helsefag [Focus Groups as Research Methods for Medicin and Health Care]. Universitetsforlaget, Oslo.

[24] Malterud, K. (2016) Sample Size in Qualitative Interview Studies: Guided by Information Power. Qualitative Health Research, 26, 1753-1760. https://doi.org/10.1177/1049732315617444

[25] Graneheim, U.H. and Lundman, B. (2004) Qualitative Content Analysis in Nursing Reserach: Concepts, Procedures and Measures to Achieve Trustworthiness. Nurse Education Today, 24, 105-112. https://doi.org/10.1016/j.nedt.2003.10.001

[26] Act of Municial Health Care Services of 24 of June 2011 [Lov om kommunale helse og omsorgstjenester av 24.Juni 2011 nr 30]. Norwegian Ministry of Health and Care Service [Helse og omsorgstjenesteloven], Oslo. https://lovdata.no/dokument/NL/lov/2011-06-24-30?q=Lov\%20om\%20kommunale

[27] Dusek, B., Pearce, N., Harripaul, A. and Lloyd, M. (2015) Care Transitions. A Systematic Review of Best Practice. Journal of Nursing Care Quality, 30, 233-239. https://doi.org/10.1097/NCQ.0000000000000097

[28] Flemming, D. and Hübner, U. (2013) How to Improve Change of Shift Handovers and Collaborative Grounding and What Role Does the Electronic Patient Record System Play? Results of a Systematic Literature Review. International Journal of Medical Informatics, 82, 580-592. https://doi.org/10.1016/j.ijmedinf.2013.03.004

[29] Patients Rights' Act of 2 July 1999 [Lov om pasient og brukerrettigheter av 2. juli 1999]. Norwegian Ministry of Health and Care Service, Oslo. https://lovdata.no/dokument/NL/lov/1999-07-02-63\#KAPITTEL 3

[30] Tobiano, G., Bucknall, T., Marshall, A., Guinane, J. and Chaboyer, W. (2015) Nurses' Views of Patient Participation in Nursing Care. Journal of Advanced Nursing, 71, 2741-2752. https://doi.org/10.1111/jan.12740

[31] Lyngsø, A.M., Godtfredsen, N.S. and Frølich, A. (2016) Interorganisational Integration: Healthcare Professionals' Perspectives on Barriers and Facilitators within the 
Danish Healthcare System. International Journal of Integrated Care, 16, 4. https://doi.org/10.5334/ijic.2449

[32] Laugaland, K., Aase, K. and Waring, J. (2014) Hospital Discharge of the Elderly-An Observational Case Study of Functions, Variability and PerformanceShaping Factors. BMC Health Services Research, 14, 365. https://doi.org/10.1186/1472-6963-14-365

[33] Jeffs, L., Lyons, R.F., Merkley, J. and Bell, C.M. (2013) Clinicians' Views on Improving Inter-Organizational Care Transitions. BMC Health Services Research, 13, 289. https://doi.org/10.1186/1472-6963-13-289

Submit or recommend next manuscript to SCIRP and we will provide best service for you:

Accepting pre-submission inquiries through Email, Facebook, LinkedIn, Twitter, etc. A wide selection of journals (inclusive of 9 subjects, more than 200 journals) Providing 24-hour high-quality service User-friendly online submission system Fair and swift peer-review system Efficient typesetting and proofreading procedure Display of the result of downloads and visits, as well as the number of cited articles Maximum dissemination of your research work

Submit your manuscript at: http://papersubmission.scirp.org/ Or contact ojn@scirp.org 